\title{
Development of a combined mean value-zero dimensional model and application for a large marine four-stroke Diesel engine simulation
}

Francesco Baldi $^{\mathrm{a}, 1}$, Gerasimos Theotokatos ${ }^{\mathrm{b}, 1,{ }^{*}},{ }^{\text {Karin Andersson }}{ }^{\mathrm{a}}$

a Department of Shipping and Marine Technology, Chalmers University of Technology, SE-41296, Gothenburg, SWEDEN

b Department of Naval Architecture, Ocean \& Marine Engineering, 100 Montrose Street, Glasgow G4 0LZ, UK

* Corresponding author. Tel.: +44(0)1415483462 E-mail address: gerasimos.theotokatos@strath.ac.uk

1 These authors contributed equally to this work

\begin{abstract}
In this article, a combined mean value-zero dimensional model is developed using a modular approach in the computational environment of Matlab/Simulink. According to that, only the closed cycle of one engine cylinder is modelled by following the zero-dimensional approach, whereas the cylinder open cycle as well as the other engine components are modelled according to the mean value concept. The proposed model combines the advantages of the mean value and zero-dimensional models allowing for the calculation of engine performance parameters including the in-cylinder ones in relatively short execution time and therefore, it can be used in cases where the mean value model exceeds its limitations. A large marine fourstroke Diesel engine steady state operation at constant speed was simulated and the results were validated against the engine shop trials data. The model provided results comparable to the respective ones obtained by using a mean value model. Then, a number of simulation runs were performed, so that the mapping of the brake specific fuel consumption for the whole operating envelope was derived. In addition, runs with varying turbocharger turbine geometric area were carried out and the influence of variable turbine geometry on the engine performance was evaluated. Finally, the developed model was used to investigated the propulsion system behaviour of a handymax size product carrier for constant and variable engine speed operation. The results are presented and discussed enlightening the most efficient strategies for the ship operation and quantifying the expected fuel savings.
\end{abstract}

Keywords: combined mean value-zero dimensional model; marine engine modelling; engine parameters mapping; variable turbine geometry; propulsion plant operating modes. 


\section{Highlights}

Development of a combined mean value-zero dimensional engine model

Application for simulating a large marine Diesel four-stroke engine

Results comparable to the respective ones of the mean value model

Enhancement of mean value models predictive ability with adequate accuracy

Appropriate where the mean value approach exceeds its limitations

\section{Introduction}

The shipping industry has been facing a number of challenges due to the unprecedented rise of fuel prices [1-3], the increasing international concern and released regulations for limiting ship emissions and their impact on the environment [4] as well as the reduction of charter rates [5]. This combination of conditions has brought the subject of energy efficiency to the agenda of the maritime industry and of the corresponding academic research.

Improvements in energy efficiency can be obtained in several areas of ship operations and design [6,7]. Among the different components responsible for energy losses on-board a ship, however, it has been widely shown that the main engine(s), and in a less extent the auxiliary engines, occupy a crucial role, as they are responsible for the conversion of the fuel chemical energy to mechanical, electrical or thermal energy for covering the respective ship demands [8]. In this respect, engine manufacturers have developed a number of measures for improving engine efficiency and reducing pollutant emissions. In electronically controlled engines $[9,10]$, timings for injection and exhaust valve opening/closing are managed by computer-controlled high-pressure hydraulic systems instead of being operated directly by the camshaft; waste heat recovery systems [11-14] are now used for recovering part of the energy rejected by the engines to produce thermal and/or electrical power; with the aim of improving the propulsion engines low loads performance, retrofitting packages for turbocharger units isolation, exhaust gas bypass and turbochargers with variable geometry turbines have been presented [15-18].

Design, experimentation and prototyping are expensive processes in manufacturing industries, and in particular in the case of marine engines. As a solution to this issue, computer modelling of engines and their systems/components has been extensively used as a mean of testing alternative options and possible improvements during the engine design phase by employing a limited amount of resources. Engine models of a varying range of accuracy and computational time can be employed depending on the required application 
$[19,20]$. Cycle mean value engine models (MVEM) [21-29] and zero-dimensional models (0-D) [30-36] are extensively used both for the evaluation of engine steady-state performance and transient response, in cases where the requirements for predicting details of the combustion phase are limited. The former are simpler and faster and provide adequate accuracy in the prediction of most engine output variables [25,29]; the latter include more detailed modelling of the engine physical processes and therefore, more realistic representation of the physical processes as well as higher accuracy can be obtained at the expense of additional computational time.

MVEMs are based on the assumption that engine processes can be approximated as a continuous flow through the engine, and hence average engine performance over the whole operating cycle. As a consequence, the in-cycle variation (per crank-angle degree) of internal parameters such as pressure and temperature cannot be estimated [27,37]. MVEMs have been extensively described in the scientific literature [38-40] and were employed for modelling of marine Diesel engines, both two-stroke [25-29] and four-stroke [21-23].

Zero dimensional (0-D) models operate per crank-angle basis by using the mass and energy conservation equations, along with the gas state equation, which are solved in their differential form, so that the parameters of the gas within the engine cylinders and manifolds, such as pressure, temperature and gas composition can be calculated. Combustion is modelled by using phenomenological models of either one zone, which are an adequate compromise of process representation and accuracy, or multi zones, which offer more detailed representation of the combustion process and prediction of exhaust gas emissions.

Both MVEMs and 0-D models offer specific trade-offs in terms of accuracy, computational time, and required input/provided output. However, when the focus lies in the energy performance and analysis of the system, it is widely recognized that the single-zone 0 -D models provide the best trade-off between computational effort and performance, whilst more advanced modelling is generally needed for obtaining additional details on pollutant formation processes [19].

MVEMs have been used to simulate marine engines operation and predict the engine performance parameters, but they cannot predict the in-cylinder parameters variation as well as the specific fuel consumption for the cases where inlet receiver pressure varies comparing with a baseline value e.g. in electronically controlled versions of marine engines or in engines using turbochargers with variable geometry turbine. On the other hand, 0-D models can handle such cases with the drawback of considerable execution time. An attempt to combine MVEMs with 0-D models were presented in Livanos et al. [41], where mapping of the cylinders using a 0-D tool was first performed and subsequently the maps were linked with a mean 
value model. The derived model was used to design the control system and test alternative control schemes for an ice-class tanker performing manoeuvres in iced sea water. In Ding et al. [42], a Seiliger cycle approach was used in conjunction with a MVEM for representing the in-cylinder process. In both cases, a considerable pre-processing phase is required; in the first case to set up and run the 0-D model as well as for elaborating the results and create the required maps; in the latter case for calibrating the Seiliger model constants based on available experimental data.

The objective of this work is to propose a modelling approach that combines the computational time of a mean value approach with the required contribution from a 0-D model for calculating in-cylinder parameters that cannot be available if a pure mean value approach was employed. This combined MV-0D modelling approach uses a 0-D model for representing the cylinder closed cycle (IVC to EVO in the case of a fourstroke engine), whereas it employs a faster mean value approach for simulating the open part of the cycle (EVO to IVC) as well as for the other engine components. In this respect, the in-cylinder parameters variation as well as the engine performance can be adequately predicted in the whole engine operating envelope, thus surpassing the limitations of the mean value models.

\section{Engine model description}

The engine model is implemented in MATLAB/Simulink environment according to a modular approach. The utilised blocks and connections are shown in Figure 1.

The engine inlet and exhaust receivers are modelled as control volumes, whereas the turbocharger compressor and turbine are modelled as flow elements. For the engine cylinders a hybrid flow elementcontrol volume approach is used as explained below. An engine governor controls the fuel flow using a proportional-integral (PI) controller law with torque and scavenging pressure limiters, whilst the engine load and the ordered speed are considered input variables to the model. The working fluid (air and exhaust gas) is considered ideal gas and therefore, the fluid properties depend on gas composition and temperature. For the calculation of the exhaust gas composition, the following species were taken into account: $\mathrm{N}_{2}, \mathrm{O}_{2}, \mathrm{H}_{2} \mathrm{O}$ and $\mathrm{CO}_{2}$.

\subsection{Shafts dynamics}

The engine crankshaft and turbocharger shaft rotational speeds are calculated according to the following equations, which represent the conservation of the angular momentum in the respective shaft lines: 


$$
\begin{aligned}
& \frac{d N_{E}}{d t}=\frac{30\left(\eta_{S h} \tau_{E}-\tau_{P}\right)}{\pi I_{S h}} \\
& \frac{d N_{T C}}{d t}=\frac{30\left(\tau_{T}-\tau_{C}\right)}{\pi I_{T C}}
\end{aligned}
$$

where $I_{S h}$ represents the total inertia of the engine-propeller shafting system including the engine crankshaft, gearbox, shafting system, propeller and entrained water inertia, $\tau$ represents the torque and $N$ the shaft speed, whilst subscripts $E, P, T, C$ and $T C$ represent the engine, propeller, turbine, compressor and turbocharger elements, respectively. The shafting system efficiency is considered a function of the engine load as described in [43].

\subsection{Turbocharger components}

The compressor is modelled using its steady state performance map, which provides the interrelations between the compressor performance variables, in specific: corrected flow rate, pressure ratio, corrected speed and efficiency. Turbocharger speed and pressure ratio are considered input to the model, which allows the computation of the corrected flow rate and efficiency through interpolation [27]. The turbocharger shaft speed is calculated in the turbocharger shaft block, whilst the compressor pressure ratio is calculated according to the following equation, which accounts for pressure losses in the air cooler and filter:

$$
p r_{C}=\frac{p_{I R}+\Delta p_{A C}}{p_{a m b}-\Delta p_{A F}}
$$

where $p r_{c}$, represents the compressor pressure ratio and the subscripts $I R, A C, A F$ and $a m b$ represent the inlet receiver, air cooler, air filter and ambient conditions, respectively. The pressure in the inlet receiver and the ambient pressure are taken from the inlet receiver and fixed fluid elements, connected downstream and upstream of the compressor element, respectively. The air filter and air cooler losses are considered to be proportional to the square of the compressor air mass flow rate.

The temperature of the air exiting the compressor is calculated according to the following equation, which was derived by using the compressor efficiency definition equation [44]:

$$
T_{C, d}=T_{C, u}\left(1+\left(p r_{C}^{\left(\gamma_{a}-1\right) / \gamma_{\alpha}}-1\right) / \eta_{C}\right)
$$

where $T_{c, d}, T_{c, u}, \gamma_{a}$ and $\eta_{c}$ represent the compressor outlet and inlet temperature, air heat capacities ratio and compressor efficiency, respectively. The compressor absorbed torque can subsequently be calculated according to the following equation: 


$$
\tau_{C}=30 \dot{m}_{C}\left(h_{C, d}-h_{C, u}\right) /\left(\pi N_{T C}\right)
$$

The specific enthalpy of the air exiting the compressor is calculated by using the respective temperature calculated from eq. (4), whereas the specific enthalpy of the air entering the compressor is taken from the fixed fluid element connected upstream.

The temperature of the air exiting the air cooler is calculated based on the air cooler effectiveness definition equation [44]:

$$
T_{A C, d}=\varepsilon T_{W}+(1-\varepsilon) \mathrm{T}_{C, d}
$$

where $\varepsilon$ and $T_{w}$ represent the air cooler effectiveness and the cooling water inlet temperature, respectively. The air cooler effectiveness is assumed to be a polynomial function of the air cooler air mass flow rate. The specific enthalpy of the air exiting the air cooler is calculated by using the respective temperature as derived by eq. (6)

The turbine is modelled using its swallowing capacity and efficiency maps, which allow the calculation of turbine flow rate and efficiency through interpolation. The turbine pressure ratio is calculated according to the following equation, by taking the exhaust pipe pressure losses into account, which are considered to be proportional to the square of the exhaust gas flow rate:

$$
p r_{T}=\frac{p_{E R}}{p_{a m b}+\Delta p_{e p}}
$$

where the subscripts $E R$ and $e p$ refer to the exhaust receiver and the exhaust pipe, respectively. The exhaust gas outlet temperature is calculated by using the turbine efficiency definition equation [44], whereas the turbine torque is derived by using the following equation:

$$
\tau_{T}=30 \dot{m}_{T}\left(h_{T, \mathrm{u}}-h_{T, \mathrm{~d}}\right) /\left(\pi N_{T C}\right)
$$

The specific enthalpy of the exhaust gas exiting the turbine is calculated by using the respective temperature, whereas the specific enthalpy of the exhaust gas entering the turbine is taken from exhaust receiver element connected upstream.

\subsection{Inlet and Exhaust receivers}

The flow receiver elements (inlet and exhaust receiver) are modelled using the open thermodynamic system concept [44-46]. By applying the mass and energy conservation laws considering that the working medium is an ideal gas, which can be represented by its pressure, temperature and equivalence ratio, and 
neglecting the dissociation effects and the kinetic energy of the flows entering/exiting the receivers, the following equations are derived for calculating the mass and temperature time derivatives:

$$
\begin{aligned}
& \frac{d m}{d t}=\dot{m}_{\text {in }}-\dot{m}_{\text {out }} \\
& \frac{d T}{d t}=\frac{\dot{Q}_{h t}+(\dot{m} h)_{\text {in }}-(\dot{m} h)_{\text {out }}-u \frac{d m}{d t}}{m c_{v}}
\end{aligned}
$$

where $\dot{m}$ and $(\dot{m} h)$ represent the mass and energy flow rates and the subscripts in and out denote the flows entering and exiting the flow receiver, respectively. Heat transfer is not considered for the inlet receiver, whereas for the case of exhaust receiver, the heat transferred from the gas to the ambient is estimated by using the temperature difference, the exhaust receiver surface and the heat transfer coefficient. The latter is calculated using a typical Nusselt-Reynolds number correlation for gas flowing in pipes [47]. The pressure of the working medium contained in the engine receivers is calculated by using the ideal gas law equation.

The properties of the working medium (air for the inlet receiver; exhaust gas for the exhaust receiver) are calculated by using the respective temperatures and the equivalence ratio for the case of exhaust receiver.

\subsection{Engine cylinder modelling}

The engine cylinders are considered to be a hybrid element that combines functionalities from the mean value and the zero dimensional approaches as explained below.

\subsubsection{Open cycle modelling}

The open part of the engine cylinders cycle (gas exchange period) is modelled by using the mean value approach. In this respect, the mass and energy flows entering and exiting the cylinders are calculated in per cycle basis. The mass flow rate of air entering the cylinders is calculated by considering the pumping mass flow rate and the scavenging flow rate (during the valve overlap period), as follows:

$$
\dot{m}_{a}=\dot{m}_{p u m p}+\dot{m}_{s c a v}
$$

The pumping mass flow rate is derived by using the following equation as function of the engine cylinders volumetric efficiency, the density of the inlet receiver, the engine displacement volume and the engine speed:

$$
\dot{m}_{\text {pump }}=\frac{\eta_{v o l} \rho_{I R} V_{D} N_{E}}{60 k}
$$

where $k$ denotes the number of revolutions per cycle. 
The engine volumetric efficiency of the process is calculated according to the following equation as suggested in [46] as a function of the engine compression ratio $\left(r_{c}\right)$ and the temperature upstream inlet valve, which is considered equal to the temperature in the inlet receiver (and therefore is taken from the inlet receiver block):

$$
\eta_{v o l}=\frac{r_{c}}{r_{c}-1} \frac{T_{I R}}{313+\frac{5}{6}\left(T_{I R}-273.15\right)}
$$

The scavenging mass flow rate is calculated according to the following equation, which was derived assuming subsonic flow consideration through the valves [44,45] during the valve overlapping period:

$$
\dot{m}_{\text {scav }}=c_{d} A_{e q} \frac{p_{I R}}{\sqrt{R_{a} T_{I R}}} \sqrt{\frac{2 \gamma_{\alpha}}{\gamma_{\alpha}-1}\left({\frac{p_{I R}}{p_{E R}}}^{\frac{2}{\gamma_{\alpha}}}-{\frac{p_{I R}}{p_{E R}}}^{\frac{\gamma_{\alpha}+1}{\gamma_{\alpha}}}\right)}
$$

The equivalent cylinders flow area $\left(A_{\text {eq }}\right)$ can be estimated using the instantaneous area variations for an engine cycle of the intake and exhaust valves, as follows:

$$
A_{e q}=\frac{z_{c y l}}{\Delta \phi_{c y}} \int_{0}^{\Delta \phi_{c y}} \frac{A_{I V}(\phi) A_{E V}(\phi)}{\sqrt{A_{I V}^{2}(\phi)+A_{E V}^{2}(\phi)}} \mathrm{d} \phi
$$

The mass flow rate of the exhaust gas exiting the engine cylinders is calculated as the sum of the air and fuel flows entering the cylinders, i.e.:

$$
\dot{m}_{e}=\dot{m}_{a}+\dot{m}_{f}
$$

The fuel mass flow is calculated by using the injected fuel mass per cylinder and per cycle, which is regarded as a function of engine fuel rack position. The latter is adjusted by the engine governor and it us modelled using a proportional-integral (PI) controller law with torque and scavenging pressure limiters, as commonly used by engine manufacturers for protecting the engine integrity during fast transients [48].

The exhaust gas equivalence ratio is calculated by using the fuel and air flow rates as well as the fuel-air stoichiometric ratio, which is a property of the utilised fuel. This is fed to the exhaust receiver and used for calculating the exhaust gas properties.

The energy rate entering the engine cylinders is calculated by using the air mass flow rate derived from eq. (11) and the specific enthalpy of air, which is taken from the inlet receiver block. The energy rate exiting the engine cylinders is calculated by applying the energy balance to the cylinders block, as described in the following equation:

$$
\dot{H}_{e}=\dot{m}_{f} L H V \eta_{\text {comb }}+\dot{H}_{a}-\dot{W}-\dot{Q}_{w}
$$


For taking into account the effects of incomplete combustion, the combustion efficiency is considered a function of exhaust gas equivalence ratio. The engine cylinders indicated power and heat transfer rate for the entire engine cycle are required in eq. (17) and therefore, this calculation is performed for each engine cycle. Eq. (17) can be compared to the way that the respective parameter is calculated for the case of MVEM, which is based on the fuel energy chemical proportion in the exhaust gas exiting the engine cylinders. The latter has to be provided as input and needs to be calibrated based on the available experimental data $[29,49]$.

\subsubsection{Closed cycle modelling}

The closed part of the cylinder cycle is modelled according to a 0-D approach by considering the following phases: compression, injection, combustion and expansion. Each phase is modelled by considering the mass and energy conservation equations along with the ideal gas state equation, the working fluid properties and the appropriate submodels to represent the engine combustion and heat transfer.

By considering the energy conservation neglecting the kinetic energy and assuming for the working medium ideal gas and homogeneous mixture, the state of which can be determined by using its pressure, temperature and composition, the following equation is derived for calculating the cylinder working internal energy time derivative:

$$
\frac{d u}{d t}=\frac{\frac{d Q_{f}}{d t}-p \frac{d V}{d t}-\dot{Q}_{w}-u \frac{d m}{d t}}{m}
$$

In the above equation, the heat release rate $\left(\mathrm{dQ}_{\mathrm{f}} / \mathrm{dt}\right)$ is calculated by using the combustion model described below. The properties of the working medium (either air or exhaust gas) were calculated as functions of temperature and gas composition [45]; dissociation effects were not taken into account. The cylinder volume and the volume derivative were calculated based on the engine kinematic mechanism particulars [45].

The ignition delay is calculated by using the following equation as proposed by Sitkei [50]:

$$
\Delta \phi_{i d}=6 \cdot 10^{-3} N\left[a_{i d}+b_{i d} e^{\frac{7800}{6.9167 R T}}\left(1.0197 p^{-0.7}\right)+c_{i d} e^{\frac{7800}{6.9167 R T}}\left(1.0197 p^{-1.8}\right)\right]
$$

where $N$ represents the engine speed in $\mathrm{r} / \mathrm{min}, T$ the gas temperature in $\mathrm{K}$, and $p$ the pressure inside the cylinder in bar; $a_{i d}, b_{i d}$, and $c_{i d}$ are constants estimated as suggested in [51] for large Diesel engines.

Combustion is modelled according to a Vibe curve, which is often referred to as a good approximation for heat release of engines burning a single fuel [51]: 


$$
\frac{d Q_{f}}{d \phi}=Q_{f, t o t} a(m+1)\left(\frac{\phi-\phi_{S O C}}{\Delta \phi_{c o m b}}\right)^{m} e^{-a\left(\frac{\phi-\phi_{S O C}}{\Delta \Delta_{c o m b}}\right)}
$$

where $\phi$ represents the crank angle in degrees, $Q_{f}$ the heat release, $\Delta \phi_{\text {comb }}$ the total combustion duration and $\phi_{S O C}$ the start of combustion. The value of the constant $a$ is related to the combustion efficiency, and was assumed equal to 5 as suggested in [53]. Constants $m$ and $\Delta \phi_{\text {comb }}$ are calibrated at the engine reference point and are updated at the other operating points according to the following equations, as proposed by Woschni and Anisits [51]:

$$
\begin{aligned}
& \Delta \phi_{c o m b}=\Delta \phi_{c o m b, r e f}\left(\frac{\lambda_{r e f}}{\lambda}\right)^{a_{c o m b}}\left(\frac{N}{N_{r e f}}\right)^{b_{c o m b}} \\
& m=\left(m_{r e f}+\Delta m\right)\left(\frac{\phi_{i d, \text { ref }}}{\phi_{i d}}\right)^{a_{m}}\left(\frac{N_{r e f}}{N}\right)^{b_{m}}\left(\frac{m_{I V C}}{m_{I V C, r e f}}\right)^{c_{m}}-\Delta m
\end{aligned}
$$

The constants $a_{c o m b}, b_{c o m b}, a_{m}, b_{m}$ and $c_{m}$ are regarded as the model calibration parameters, since they can sensibly differ amongst various engines types and sizes as reported in [51].

The cylinder heat losses (from working medium to cylinder walls) are calculated using the standard equation for convective heat transfer assuming a constant value for the cylinder walls temperature:

$$
\dot{Q}_{w}=h A\left(T_{c y l}-T_{w}\right)
$$

The average of cylinder heat losses over one engine cycle was calculated and used in eq. (17). For calculating the heat transfer coefficient from cylinder gas to wall, the Woschni correlation was used [19,51]:

$$
h=127.93 p^{0.8} w^{0.8} d^{-0.2} T^{-0.53}
$$

where $p$ represents the cylinder pressure in bar, $d$ the cylinder diameter in $\mathrm{m}, T$ the cylinder gas temperature in $\mathrm{K}$ and $w$ is a representative velocity that takes into account the mean piston speed and the combustion induced turbulence.

Eq. (18)-(24) along with the mass conservation and the ideal gas equations form a system of equations that is solved for each crank angle step of the closed cycle from IVC to EVO. A variable time step approach was used with the upper limit equal to 2 degrees crank angle.

\subsubsection{Calculation procedure}

The graphical representation of the cylinder model including the interconnections between the cylinder 
block components and the other engine elements are shown in Figure 2. The input from the adjacent elements include: the pressure, temperature and specific enthalpy from inlet receiver; the pressure from the exhaust receiver; the rack position from governor; and the engine speed from shaft element. The injected fuel amount is calculated by using the rack position and subsequently it is used along with the engine speed for the calculation of the fuel mass flow rate. Using the MV approach, the cylinders air and exhaust gas mass flow rates as well as the energy flow of the air entering the engine cylinders and the equivalence ratio of the exhaust gas exiting the cylinders are calculated.

Based on the inlet receiver pressure and temperature, the initial cylinder pressure and temperature for the start of closed cycle are derived. In specific, the cylinder pressure at the IVC is assumed equal to the inlet receiver pressure; the temperature at IVC is assumed equal to the inlet receiver temperature increased by a reasonable value in order to account for the mixing with the residual exhaust gas [54]; the working medium at IVC is assumed to be air, since the residual exhaust gas fraction is generally small in four-stroke marine Diesel engines [20] and its influence on the prediction of the trapped gas during the compression phase is therefore limited.

The additional input of the 0-D model includes the engine geometry and the model constants as well as the crank angle at IVC and the crank angle step. The pressure, temperature, heat release and heat loss are calculated for the closed cycle and the total closed cycle work and heat loss are derived. The output of the MV and 0-D models are combined for calculating the remaining cylinder performance parameters including the energy flow of the exhaust gas exiting cylinders, the indicated power, the friction power, the brake power, and torque, the brake specific fuel consumption and the engine brake efficiency.

In specific, the indicated mean effective pressure is derived by elaborating the calculated cylinder pressure diagram for the closed cycle and taking into account the pumping work for the open cycle; the latter is the product of the cylinder pressure difference and the engine cylinders displacement volume. The engine brake mean effective pressure is calculated by subtracting the friction mean effective pressure from the indicated mean effective pressure, whereas the engine torque is calculated using the brake mean effective pressure and engine cylinders displacement volume. Several correlations were proposed for the modelling of friction mean effective pressure. In this study, the mean of the correlations proposed by Chen and Flynn [55] and McAuley et al. [56], which are both linear functions of engine speed and maximum pressure, was used.

Then, the calculated parameters are forwarded to the adjacent engine components as shown in Figure 2. The mass and energy flow rates of the air entering cylinder are provided to the inlet receiver element; the 
exhaust gas mass and energy flow rates along with the gas equivalent ratio are advanced to the exhaust receiver element; and the engine torque is transferred to the shaft element.

\subsection{Model set up procedure and constants calibration}

For setting up a new engine morel, the subsequent steps are followed:

- Selection and connection of the blocks representing the engine components.

- Insertion of the required input data in each block.

- $\quad$ Preliminary calibration of the model constants for a reference point.

- $\quad$ Fine tuning of the model constants.

The following input data are needed to set up the model: the engine geometric data, the equivalent area of the cylinder intake and exhaust valves, the steady state compressor and turbine performance maps, the constants of engine combustion model, the propeller loading and the ambient conditions. For integrating the time derivatives of the model governing equations, initial values are also required for the following variables: the engine/propeller and turbocharger rotational speeds, the temperature and pressure of the working medium contained in the engine receivers.

The three main engine parameters describing the combustion (Vibe curve parameters) are not usually known beforehand and need to be determined through a training procedure. The combustion model was initially calibrated versus shop trials performance data for the engine maximum continuous rating (MCR) point, which was considered as the reference point, in order to determine the range for Vibe curve parameters $\Delta \phi_{c o m b, r e f}$ and $m_{\text {comb,ref. }}$ The parameters defining the shape of the heat release rate function in other engine operating points (eq. 21-22), are calibrated by using the full set of shop trial data. The values proposed by Woschni-Anisits for large two-stroke Diesel engines and heavy duty four-stroke engines are used as boundaries. Finally, all combustion model parameters were fine-tuned at the full engine model. This multiplelevel calibration procedure allows for reducing the model set-up time. All calibration steps were performed using a Genetic Algorithm, which had been previously utilized [31] providing promising results.

\section{Test case}

The four-stroke marine Diesel engine MaK 8M32C was simulated using the described combined MV-0D engine model. The MaK $8 \mathrm{M} 32 \mathrm{C}$ is a four stroke, eight cylinders in line, turbocharged engine; one turbocharger unit is used, whereas an air cooler is installed between the compressor and the inlet receiver. The 
main engine characteristics as well as the required input data were gathered from the engine project guide [57].

Medium speed engines of this size are normally used as propulsion and auxiliary engines in RoRo vessels, small tankers and bulk carriers. For the present study, the propulsion plant arrangement of a handymax size chemical tanker was selected for testing the model predictive ability. In this arrangement, two engines provide power to the ship propeller and one shaft generator unit; a gearbox of two inputs (the shaft of each engine) and two outputs (shaft generator, propeller) is used as shown Figure 3. The propeller is of the controllable pitch type, whereas the engine/propeller gearbox ratio is 5.68. Additionally to the shaft generator, the vessel power plant includes two diesel generator sets having a rated power of $690 \mathrm{kWe}$ for providing the required electrical power in cases where the propulsion engines or the shaft generator are not in operation. The main characteristics of the vessel and each propulsion engine are summarized in Table 1.

\section{Model set up and validation}

The engine model was set up providing the required input data, including engine geometric data, turbocharger compressor and turbine steady-state performance maps, model constants and initial conditions. For the investigated engine, the engine shaft speed was used as control variable for the PI regulator and therefore, its initial value was set equal to the desired engine speed value. For the case of the receivers' pressure and temperature, polynomial regressions as a function of engine load were used to estimate the initial conditions derived from the shop trial measurements. The fuel was assumed to be of the marine diesel oil (MDO) type with a lower heating value equal to $42.4 \mathrm{MJ} / \mathrm{kg}$ as this fuel type was used in the engine trials. This value was also used for calculating the engine brake specific fuel consumption (bsfc) presented below.

The combustion model constants were calibrated as described in Section 2.5 by using the engine performance data from engine shop trials. Measurements for the engine efficiency and the exhaust gas temperature at turbine inlet at $100 \%$ load were used for training the model, whereas measurements at other loads $(50 \%, 85 \%$, and $110 \%$ of the engine MCR) were used for the model validation. The relative errors for the brake specific fuel consumption and the exhaust gas temperature at turbine inlet were used in both cases for determining the objective function used by the genetic algorithm, as described by the following equation:

$$
f_{o b j}=\sum_{i} w_{i}\left|\Delta z_{r e l, i}\right|
$$

The calibrated combustion model parameters are shown in Table 2. It must be noted that the $\Delta m$ parameter was optimized at a value outside the original boundaries in order to provide a better match for $b s f c$ variation 
at low loads.

The steady state simulation results at constant engine speed (equal to $600 \mathrm{r} / \mathrm{min}$ ) are presented in Figure 4. In addition, Table 3 contains the obtained percentage relative errors between the parameters calculated using the MVEM, the combined MV-0D model and the respective measured data. The results presented in Table 3 show that the combined model presented herein exhibits reasonable accuracy over the entire engine operating range. It can be inferred that the performance of the two models (MVEM and combined MV-0D) are comparable. The combined MV-0D model shows a slight tendency of underestimating engine brake specific fuel consumption at $50 \%$ load, with an error which is however lower than the standard tolerance employed by the marine engine manufacturers. The obtained agreement between the predicted and measured values for the MVEM is better, which is attributed to the effective calibration process for this model. However, it must be noted that the MVEM is placed closer to a black-box model than the proposed combined MV-0D alternative [57].

\section{Model application}

Having validated the engine model, it was possible to use it in order to investigate various engine operating cases. The steady-state performance over a range of engine loads from $50 \%$ to $110 \%$ (using $5 \%$ load increase step) at constant engine speed $(600 \mathrm{r} / \mathrm{min})$ was first examined. The derived engine parameters including the brake specific fuel consumption (bsfc), the turbocharger speed, the pressure at compressor outlet and the exhaust gas temperature at turbine inlet and outlet are shown in Figure 4. Values predicted by the combined model are shown, along with the respective predictions obtained using the MVEM model as well as the measured values from shop trials at 50\%, 85\%, 100\% and $110 \%$ loads. Once again, good agreement between measured and predicted results by the combined MV-0D and the mean value models can be observed throughout the investigated engine operating envelope. It is inferred from the engine parameters presented in Figure 4, the engine was optimised at the high loads region, since the minimum brake specific fuel consumption is obtained at $85 \%$ load and the minimum turbine outlet temperature is observed at $100 \%$ load. This reflects the market conditions when the ship was designed and built, when slow-steaming and low speed operations were not considered as a possible operating mode.

Figure 5 shows the cylinder pressure diagrams, which can be calculated by using the proposed combined MV-0D approach and are not available for the case of the MVEM. The cylinder maximum pressure at $100 \%$ load was only available and used for initially calibrating the combustion model at this operating point. The 
relative percentage error that was finally obtained for this parameter at MCR point was $0.8 \%$. As the incylinder pressure variation can be predicted by the combined model, this model can be used in the cases were this feature is needed, as an alternative to a $0-\mathrm{D}$ model, which is more complex and computationally demanding. Figure 6 shows the calculated heat losses to cylinder walls, charge air cooler and exhaust gas for various engine loads. Experimental values for the engine heat losses were not available for validation. Therefore, the results from the proposed combined model are compared with the results from the MVEM; the maximum relative percentage differences for the energy flows of the charge air cooler and the exhaust gas were found to be $9.4 \%$ and $7.3 \%$, respectively. The prediction of heat losses to the cylinder walls is a result of the combination of the MV and 0-D models, since the calculation of in-cylinder temperature over the closed cycle allows for the utilization of the Woschni correlation for the estimation of cylinder heat losses. These results can be of particular interest in the design and optimization of engine cooling and waste heat recovery systems.

\subsection{Engine brake specific fuel consumption map}

For the investigated engine, no measurements or data were available at speeds different than the nominal. By using 0-D or the combined model proposed in this work, the estimation of the effect of engine speed on the engine efficiency and on the other parameters can be provided. MVEMs, however, are intrinsically unable to take this effect into account, since the in-cylinder processes are not modelled. The proposed model can provide the required fidelity in the prediction of the influence of engine speed on efficiency.

Figure 7 shows the results from the application of the model to predict the engine brake specific fuel consumption within the engine power-speed region. It must be noted that the operating envelope of the investigated engine is very narrow and therefore it allows for only limited reduction in engine speed. As expected, the engine speed has the highest impact on engine efficiency in the region close to the upper boundary of the operating envelope, whilst at lower loads the engine efficiency becomes rather insensitive to the engine speed variation. However, a slight bsfc improvement (1-2 g/kWh) could be achieved by operating at an optimal engine speed, which provides the minimum bsfc at each engine load. The utilization of the proposed model allows for the extension of the efficiency map to the whole engine operating envelope, which is not available from the engine shop tests, the sea trials or the engine project guide. Thus, the more detailed modelling approach followed for the development of the proposed combined model, when compared to mean value models, provides a higher ability of predicting the engine behaviour outside the operational conditions 
for which the model constants have been calibrated.

\subsection{Variable Geometry Turbine effects on engine performance}

The limited size of the allowed speed range for the test-case engine renders a strong limitation for considerable efficiency improvement of the vessel overall propulsion train, since optimal operations at a lower ship speed (e.g. reduction from 15 knots to 12 knots) would require a reduction of the engine speed, which is not permitted for the investigated engine [57]. Reducing turbine area can improve the engine charging process at low loads and consequently can reduce the exhaust gas temperatures. Therefore it is a widely recognized method for broadening the turbocharged engines operating envelope at low loads [15]. Since measurements with a different turbocharger turbine area were not available, the combined model can be used to predict the engine behaviour in this case. On the contrary, MVEMs are not able to fully simulate the effect of increased air charge pressure on engine efficiency and in-cylinder performance parameters. The model derived results using turbine geometric area values in the range from $90 \%$ to $110 \%$ of its original value for fixed engine speed operation $(600 \mathrm{r} / \mathrm{min})$ are presented in Figure 8.

Reducing turbine inlet area has the main impact of increasing the pressure at turbine inlet, thus providing more exhaust gas energy to the turbine, which increases the turbocharger speed and as a result, the engine inlet receiver pressure. The latter increases the maximum cylinder pressure, which has as a consequence the increase of the engine efficiency and therefore, the decrease of the brake specific fuel consumption. The opposite happens in the case of increasing the turbine geometric area. The above described behaviour is clearly shown in Figure 8. However, if the turbine geometric area decrease is too large, the engine efficiency may deteriorate and the maximum cylinder pressure might increase above the allowed limit.

The effect of a higher air mass flow rate is also shown in Figure 8, where the equivalence ratio is shown for different values of turbine inlet area. The increase of the equivalence ratio results in a decrease of the peak temperatures and as a result, in lower engine thermal loading. This behaviour, also shown in Figure 8, can potentially lead to an extended operational envelope towards lower loads for a given engine speed.

As it was explained above, reducing the inlet turbine area causes an increase in turbocharger speed. At low engine loads, however, the turbocharger speed is far from its high limit and therefore, it should not present a confining factor. In this case, the engine in-cylinder pressure level increases at low loads, which results in a more efficient engine operation. 


\subsection{Propulsion plant variable speed operation}

The model ability to predict the engine performance at different loads and speeds was employed in order to test the potential for improving the operational efficiency of the investigated vessel propulsion plant. The two alternative operational modes that are compared are as follows: (a) the propulsion plant operates with constant engine speed equal to $600 \mathrm{r} / \mathrm{min}$ and the shaft generator is used to supply the required electrical power; and (b) the diesel generator sets are used for covering the ship electrical power demand, which allows for operations at variable propeller and engine speeds. The required ship electrical power was set to $400 \mathrm{kWe}$ based on available measurements from on-board power system.

The rationale for operating at variable propeller speed is attributed to the fact that the propeller efficiency depends on its rotational speed as it is shown in Figure 9. Hence, operations at constant propeller speed, although allowing for the generation of the ship electrical energy at higher efficiency, lead to lower propeller efficiency at ship speeds lower than the design speed.

The two alternative operational modes were tested for various ship speeds in the range from 10 to 14 knots. The ship resistance was regarded as a polynomial function of the ship speed, whereas the propeller efficiency was derived using the Wageningen series polynomials as described in [58]. The proposed combined MV-0D engine model was used to predict the engine performance under fixed or variable engine speed operating conditions. The following input was additionally used for modelling the two considered cases: i) gearbox efficiency at full load $98 \%$; ii) shafting system efficiency at full load $99 \%$; iii) shaft generator efficiency at rated power $95 \%$; iv) diesel generators bsfc $210 \mathrm{~g} / \mathrm{kWh}$ (one diesel generator set operates at $57 \%$ load for generating the required electrical power); v) electric generator efficiency at the considered operating point equal to $95 \%$. The rated efficiencies for the gearbox, shafting system and shaft generator are corrected as proposed in [43] for operation at part loads.

The following additional equations were used for the propulsion system modelling under steady state operating conditions:

$$
\begin{aligned}
& \eta_{G B}\left(P_{E 1}+P_{E 2}\right)=P_{s h}+P_{S G} \\
& P_{S G}=P_{e l} / \eta_{S G} \text { and } P_{s h}=P_{p} / \eta_{s h} \\
& \dot{m}_{A E}=b s f c_{A E} P_{e l} / \eta_{E G}
\end{aligned}
$$

The derived results including the propeller power, the engine bsfe for each operating engine, the engine load and speed, the total fuel flow demand for the operating propulsion engines and diesel generator sets, are shown in Figure 10. Due to the more efficient propeller operation at the variable speed mode (case b), lower 
propeller power in this operating mode is required at the entire investigated speed range. It must be noted that for constant engine speed operation (case a), two engines need to operate for ship speed greater than 10.4 knots, whereas for ship speed lower than this, one engine can cover the required total power demand (propulsion and electrical). For the variable engine speed operation (case b), the break point for reducing the number of operating engines from two to one is at 11.8 knots. Therefore, in both cases the maximum engine bsfc point is observed at the break points, since the load of the operating engine increases after switching off one engine unit and consequently the engine bsfc decreases till the engine load reaches the operating point having the minimum bsfc. The engine bsfc is generally lower when operating at variable engine speed, which depends on a combination of the effects of the higher engine load and the lower engine speed.

The calculated total fuel flow demand demonstrates that fuel consumption savings in the range between $1 \%$ and $6 \%$ can be obtained when operating at variable engine speed even if the ship electrical power is covered by the less efficient diesel generator sets. Figure 11 shows a breakdown of the different contributions to the total fuel flow demand, which can explain the observed fuel savings. The largest part of the fuel improvement at the variable engine speed mode is attributed to the reduction of propeller power (as a consequence of the propeller efficiency increase). The engine running at different loads, as a consequence of the varying power demand, contributes positively or negatively on the fuel flow demand depending on the ship speed. It must be noted that the contribution at lower ship speeds, which is of the highest interest given the current slow-steaming operations used by shipping companies, is beneficial to reduce the fuel flow demand. In addition, operating at lower engine speeds also provides a considerable reduction in fuel flow demand, although this effect is more pronounced at higher ship speeds. As it was expected, the electrical power generation is substantially more efficient when operating at constant speed by using the shaft generator.

It can be concluded from the presented case studies that the developed MV-0D engine model can be used as an alternative to the 0-D models, in studies where varying engine operating conditions in terms of load and speed prevail. The usage of MVEMs is not recommended as calibration of the model constants in a broader engine operating envelope is needed unless extensive experimental data are available.

\section{Conclusions}

A combined mean-value-zero dimensional model was developed and the simulation of a large marine four stroke Diesel engine was performed. The results were validated against available engine performance 
parameters measured during engine shop trials and additionally, they were compared with results obtained by using a mean value engine model. Then, the model was used to simulate a number of engine operating points and the results were used for generating the brake specific fuel consumption map in the whole engine operating envelope. Furthermore, cases with varying the turbine geometric area were simulated, so that the model usefulness and superiority against mean value models are presented.

The main conclusions derived from the present work are summarised as follows.

The proposed model can be seen as a compromise between the more empirical mean value models and the more detailed zero dimensional models and can be used in cases where the additional features provided by the 0-D approach are required. The model set up and calibration is faster than the respective one for the 0-D models as only the closed cycle of one engine cylinder is additionally modelled. The calibration of the combustion model parameters is required, which is not too demanding compared with the calibration of the cylinder sub-model for mean value model that requires access to engine performance data and a considerable pre-processing phase.

The model execution time is only slightly greater than the one of the mean value model. In addition, the model prediction capability is quite adequate as it was revealed by the derived parameters comparison against experimental data. The proposed model predicted parameters were comparable with the respective parameters obtained by using the mean value model. The model output parameter set is enhanced, as it additionally includes the in-cylinder parameters, such as pressure, temperature and heat transfer rate. In this respect, the engine efficiency and brake specific fuel consumption can be reasonably predicted in the whole engine operating envelope (with varying load and speed) and in cases where the engine settings change (e.g. variable injection timing and variable geometry turbine).

The model can be used for creating response surfaces for the calculated engine parameters covering the whole operating envelope. The influence of the engine settings on the engine performance are taken into account, since the closed cycle is modelled. Therefore, there is no need for recalibrating the engine cylinder sub-models, as it is required for the mean value models.

The additional case studies of the engine with installed a variable geometry turbine and the vessel propulsion system that can operate in different operating modes revealed the developed model capability of predicting the engine and propulsion system behaviours, respectively. Therefore, the model can effectively assist in the identification of the most efficient engine/propulsion system operations, thus contributing to the quantification of the fuel savings potential. 
In conclusion, the combined mean value-zero dimensional model can be used in studies where the mean value model reaches its limitations, especially considering the simulation of electronically controlled versions of marine engines, as well as for simulating engines equipped with variable geometry turbine turbochargers and engine operating in an varying range of operating conditions.

\section{REFERENCES}

[1] García-Martos C, Rodríguez J, Sánchez MJ. Modelling and forecasting fossil fuels, $\mathrm{CO}_{2}$ and electricity prices and their volatilities. Appl Energy 2013;101:363-75.

[2] Zhang C, Chen X. The impact of global oil price shocks on China's bulk commodity markets and fundamental industries. Energy Policy 2014;66:32-41.

[3] Zhang Y-J, Wang Z-Y. Investigating the price discovery and risk transfer functions in the crude oil and gasoline futures markets: Some empirical evidence. Appl Energy 2013;104:220-8.

[4] IMO. Air pollution and energy efficiency-estimated $\mathrm{CO}_{2}$ emissions reduction from introduction of mandatory technical and operational energy efficiency measures for ships. MEPC 63/INF.2 2011.

[5] UNCTAD. Chapter 3: Freight rates and maritime transport costs. Rev. Marit. Transp. 2013, 2013.

[6] Buhaug O, Corbett JJ, Endersen O, Eyring V, Faber J, Hanayama S, et al. Second IMO GHG Study 2009. London, UK: International Maritime Organization (IMO); 2009.

[7] Faber J, Nelissen D, St Amand D, Consulting N, Balon T, Baylor M, et al. Marginal Abatement Costs and Cost Effectiveness of Energy-Efficiency Measures. 2011.

[8] Baldi F, Johnson H, Gabrielii C, Andersson K. Energy and exergy analysis of ship energy systems-the case study of a chemical tanker. Proc. 27th Int. Conf. Effic. Cost, Optim. Simul. Environ. Impact Energy Syst., Turku, Finland: 2014.

[9] Brunner H. Upgrade of Wartsilas Two-Stroke Engine Portfolio to fulfil the Changing Marine Market Requirement. Proc. Congr. Int. Counc. Combust. Engines, Shanghai, China: 2013.

[10] Jakobsen SB, S MANDA, Egeberg C. Service Experience of MAN B\&W Two Stroke Diesel Engines. Proc. Congr. Int. Counc. Combust. Engines, Vienna, Austria: 2007.

[11] Mest S, Diesel MAN, Loewlein O, Balthasar D, Schmuttermair H. TCS-PTG - MAN Diesel \& Turbo ' s power turbine portfolio for waste heat recovery. Proc. Congr. Int. Counc. Combust. Engines, Shanghai, China: 2013.

[12] Nielsen RF, Haglind F, Larsen U. Design and modeling of an advanced marine machinery system including waste heat recovery and removal of sulphur oxides. Energy Convers Manag 2014;85.

[13] Livanos G aA., Theotokatos G, Pagonis D-N. Techno-economic investigation of alternative propulsion plants for Ferries and RoRo ships. Energy Convers Manag 2014;79:640-51. 
[14] Hou Z, Turbo ABB. New Application Fields for Marine Waste Heat Systems by Analysing the Main Design Parameters. Proc. Congr. Int. Counc. Combust. Engines, Vienna, Austria: 2007.

[15] Schmuttermair H, Diesel MAN, Se T, Fernandez A, Witt M. Fuel Economy by Load Profile Optimized Charging Systems from MAN. Proc. Congr. Int. Counc. Combust. Engines, Bergen, Norway: 2010.

[16] Ono $\mathrm{Y}$, Industries MH. Solutions for better engine performance at low load by Mitsubishi turbochargers. Proc. Congr. Int. Counc. Combust. Engines, Shanghai, China: 2013.

[17] Lamaris V, Antonopoulos A, Hountalas D. Evaluation of an Advanced Diagnostic Technique for the Determination of Diesel Engine Condition and Tuning Based on Laboratory Measurements. SAE Tech Pap No 2010-01-0154 2010.

[18] Ahmed FS, Laghrouche S, Mehmood A, El Bagdouri M. Estimation of exhaust gas aerodynamic force on the variable geometry turbocharger actuator: 1D flow model approach. Energy Convers Manag 2014;84:436-47.

[19] Kumar S, Kumar Chauhan M. Numerical modeling of compression ignition engine: A review. Renew Sustain Energy Rev 2013;19:517-30.

[20] Stone R. Introduction to internal combustion engines. Third Edit. Palgrave Macmillan; 1999.

[21] Malkhede DN, Seth B, Dhariwal HC. Mean Value Model and Control of a Marine Turbocharged Diesel Engine. Powertrain Fluid Syst. Conf. Exhib., San Antonio, USA: 2005.

[22] Schulten PJM, Stapersma D. Mean Value Modelling of the Gas Exchange of a 4-stroke Diesel Engine for Use in Powertrain Applications. 2003 SAE World Congr., Detroit, USA: 2003.

[23] Grimmelius HT, Boonen EJ, Nicolai H, Stapersma D. The integration of mean value first principle Diesel engine models in dynamic waste heat and cooling load analysis. Proc. Congr. Int. Counc. Combust. Engines, Bergen, Norway: 2010.

[24] Weinrich M, Bargende M. Development of an Enhanced Mean-Value-Model for Optimization of Measures of Thermal-Management. SAE Tech Pap 2008:1-1169.

[25] Theotokatos GP. Ship Propulsion Plant Transient Response Investigation using a Mean Value Engine Model. Int J Energy 2008;2:66-74.

[26] Guan C, Theotokatos G, Zhou P, Chen H. Computational investigation of a large containership propulsion engine operation at slow steaming conditions. Appl Energy 2014;130:370-83.

[27] Theotokatos G, Tzelepis V. A computational study on the performance and emission parameters mapping of a ship propulsion system. Proc Inst Mech Eng, Part M J Eng Marit Environ 2015;229:58-76.

[28] Dimopoulos GG, Georgopoulou CA, Kakalis NMP. Modelling and optimization of an integrated marine combined cycle system. Proc. Int. Conf. Effic. Cost, Optim. Simul. Environ. Impact Energy Syst., Novi Sad: 2011.

[29] Theotokatos G. On the cycle mean value modelling of a large two-stroke marine Diesel engine. Proc Inst Mech Eng , Part M J Eng Marit Environ 2010;224:193-205. 
[30] Catania AE, Finesso R, Spessa E. Predictive zero-dimensional combustion model for di diesel engine feed-forward control. Energy Convers Manag 2011;52:3159-75.

[31] Scappin F, Stefansson SH, Haglind F, Andreasen A, Larsen U. Validation of a zero-dimensional model for prediction of $\mathrm{NO} x$ and engine performance for electronically controlled marine two-stroke diesel engines. Appl Therm Eng 2012;37:344-52.

[32] Asad U, Tjong J, Zheng M. Exhaust gas recirculation - Zero dimensional modelling and characterization for transient diesel combustion control. Energy Convers Manag 2014;86:30924.

[33] Finesso R, Spessa E. A real time zero-dimensional diagnostic model for the calculation of incylinder temperatures, HRR and nitrogen oxides in diesel engines. Energy Convers Manag 2014;79:498-510.

[34] Benvenuto G, Campora U, Carrera G, Casoli P. A two-zone Diesel engine model for the simulation of marine propulsion plant transients. Proc. Int. Conf. Mar. Ind., Varna, Bulgaria: 1998.

[35] Kyrtatos NP, Theotokatos G, Xiros NI, Marek K, Duge R, Engineer CS, et al. Transient Operation of Large-bore Two-stroke Marine Diesel Engine Powerplants: Measurements and Simulations. Proc. Congr. Int. Counc. Combust. Engines, vol. 4, Hamburg, Germany: 2001, p. 1237-50.

[36] Kyrtatos NP. Propulsion control optimization using detailed simulation of engine/propeller interaction. Proc. Sh. Control Syst. Symp., vol. 1, Southampton, UK: 1997, p. 507-30.

[37] Xiros NI. Robust control of Diesel ship propulsion. Springer Berlin Heidelberg; 2002.

[38] Benson RS. The thermodynamics and gas dynamics of internal combustion engines. Clarendon Press; 1986.

[39] Eriksson L. Modeling and control of turbocharged SI and DI engines. Oil Gas Sci Technol Rev I'IFP 2007;62:523-38.

[40] Guzzella L, Onder C. Introduction to Modeling and Control of IC Engine Systems. Berlin: Springer; 2009.

[41] Livanos G, Kyrtatos NP, Papalambrou G, Christou, A. Electronic Engine Control for Ice Operation of Tankers. Proc. Congr. Int. Counc. Combust. Engines, No 44, Viena, Austria: 2007.

[42] Ding Y, Stapersma D, Knoll H, Grimmelius HT, Netherland T. Characterising the Heat Release in a Diesel Engine: A comparison between Seiliger Process and Vibe Model. Proc. Congr. Int. Counc. Combust. Engines, Bergen, Norway: 2010.

[43] McCarthy WL, Peters WS, Rodger DR. Marine Diesel power plant practices. The Society of Naval Architects \& Marine Engineers, T\&R Bulletin 3-49. Jersey City, US: 1990.

[44] Watson N, Janota MS. Turbocharging the internal combustion engine. Macmillan Press; 1982.

[45] Heywood JN. Internal Combustion Engine Fundamentals. McGraw-Hill; 1988. 
[46] Hiereth H, Prenninger P. Charging the internal combustion engine. Vienna, Austria: SpringerVerlag; 2003.

[47] Bejan A, Kraus AD. Heat Transfer Handbook. Hoboken, US: John Wiley \& Sons LTd; 2003.

[48] Kyrtatos NP, Theodossopoulos P, Theotokatos G, Xiros NI. Simulation of the overall ship propulsion plant for performance prediction and control. MarPower99 Conf., Newcastle upon Tyne, UK: The institute of marine engineers; 1999.

[49] Meier E. A simple method of calculation and matching turbochargers. Publication CH-T 120 163 E. Baden, Switzerland: 1981.

[50] Sitkei G. Über den dieselmotorischen Zündverzug. MTZ; 1963.

[51] Merker GP, Schwarz C, Stiesch G, Otto F. Simulating Combustion. Berlin Heidelberg: SpringerVerlag; 2004.

[52] Ding Y. Characterising Combustion in Diesel Engines. TU Delft, 2011.

[53] Gogoi TK, Baruah DC. A cycle simulation model for predicting the performance of a diesel engine fuelled by diesel and biodiesel blends. Energy 2010;35:1317-23.

[54] Ferguson CR, Kirkpatrick AT. Internal combustion engines: applied thermosciences. 2nd ed. New York: Wiley; 2001.

[55] Chen SK, Flynn P. Development of a compression ignition research engine. SAE Pap 650733 1965.

[56] McAulay KJ, Wu T, Chen SK, Borman GL, Myers PS, Uyehara A. Development and Evaluation of the Simulation of the Compression-Ignition Engine. SAE Tech Pap 1965;650451.

[57] MaK. M32C Project Guide - Propulsion 2013.

[58] Carlton J. Marine propellers and Populsion. $3^{\text {rd }}$ ed. Butterworth-Heinemann. Oxford; 2012. 


\begin{tabular}{|c|c|c|c|}
\hline \multicolumn{4}{|c|}{ Nomenclature } \\
\hline$A$ & area $\left(\mathrm{m}^{2}\right)$ & a & air \\
\hline$B M E P$ & brake mean effective pressure (bar) & $\mathrm{amb}$ & ambient \\
\hline$b s f c$ & brake specific fuel consumption (g/kW h) & $A C$ & air cooler \\
\hline$c_{d}$ & discharge coefficient & $A E$ & Auxiliary engines \\
\hline$c_{V}$ & specific heat at constant volume $(\mathrm{J} / \mathrm{kg} \mathrm{K})$ & $A F$ & air filter \\
\hline$d$ & Cylinder bore (m) & $\mathrm{comb}$ & combustion \\
\hline$h$ & $\begin{array}{l}\text { specific enthalpy }(\mathrm{J} / \mathrm{kg}) \text {; heat transfer } \\
\text { coefficient }\left(\mathrm{W} / \mathrm{m}^{2} \mathrm{~K}\right)\end{array}$ & cor & corrected \\
\hline$H R$ & Heat release rate $(\mathrm{J} / \mathrm{deg} \mathrm{CA})$ & cy & cycle \\
\hline$\dot{H}$ & Energy flow (W) & cyl & cylinder \\
\hline$I$ & Polar moment of Inertia $\left(\mathrm{kg} \mathrm{m}^{2}\right)$ & $C$ & compressor \\
\hline$L H V$ & fuel power heating value $(\mathrm{J} / \mathrm{kg})$ & $d$ & downstream \\
\hline$k$ & Coefficients; revolutions per cycle & $E$ & engine \\
\hline$m$ & mass $(\mathrm{kg})$ & $e$ & exhaust gas \\
\hline$\dot{m}$ & mass flow rate $(\mathrm{kg} / \mathrm{s})$ & el & electrical \\
\hline$N$ & rotational speed $(\mathrm{r} / \mathrm{min})$ & ep & exhaust pipe \\
\hline$p$ & pressure $(\mathrm{Pa})$ & $e q$ & equivalent \\
\hline$p r$ & pressure ratio & $E R$ & exhaust receiver \\
\hline$P$ & power $(\mathrm{W})$ & $E V$ & exhaust valve \\
\hline$Q$ & heat transfer $(\mathrm{J})$ & EVO & Exhaust valve open \\
\hline$\dot{Q}$ & heat transfer rate $(\mathrm{W})$ & $f$ & fuel \\
\hline$R$ & gas constant $(\mathrm{J} / \mathrm{kg} \mathrm{K})$ & $G B$ & gearbox \\
\hline$r_{c}$ & compression ratio & $h t$ & Heat transfer \\
\hline$t$ & time (s) & id & ignition delay \\
\hline$T$ & temperature $(\mathrm{K})$ & in & inlet \\
\hline$u$ & specific internal energy $(\mathrm{J} / \mathrm{kg})$ & $I R$ & inlet receiver \\
\hline$V$ & Volume & IV & inlet valve \\
\hline$V_{D}$ & Engine displacement volume $\left[\mathrm{m}^{3}\right]$ & $I V C$ & inlet valve closing \\
\hline$w$ & Velocity (m/s);weight factors (-) & $M E$ & Main engines \\
\hline$W$ & Work (J) & out & outlet \\
\hline$z_{c y l}$ & number of engine cylinders & pump & pumping \\
\hline \multicolumn{2}{|c|}{ Greek symbols } & $P$ & propeller \\
\hline$\gamma$ & ratio of specific heats & ref & reference \\
\hline$\Delta$ & difference & scav & scavenging \\
\hline$\Delta \phi$ & Crank angle difference (deg) & $S G$ & Shaft generator \\
\hline$\Delta \phi_{c y}$ & engine cycle duration (deg) & $S h$ & shafting system \\
\hline$\varepsilon$ & Air cooler effectiveness & SOC & start of combustion \\
\hline$\eta$ & Efficiency & $T$ & turbine \\
\hline$\lambda$ & Air-fuel equivalence ratio (-) & $T C$ & turbocharger \\
\hline$\rho$ & density $\left(\mathrm{kg} / \mathrm{m}^{3}\right)$ & tot & total \\
\hline$\phi$ & crank angle (deg) & $u$ & upstream \\
\hline \multirow[t]{3}{*}{$\tau$} & torque $(\mathrm{Nm})$ & vol & volumetric \\
\hline & & $w$ & wall \\
\hline & & $W$ & Cooling water \\
\hline
\end{tabular}




\section{List of Figures captions}

Figure 1: Matlab/Simulink implementation of marine Diesel engine model

Figure 2: Graphical representation of the interconnections between the combined MV-0D model and the other engine model elements

Figure 3: Schematic representation of ship power plant

Figure 4: Steady-state simulation results and comparison with shop trials data

Figure 5: Combined MV-0D model calculated cylinder pressure diagrams for various engine loads

Figure 6: Calculated cooling power and exhaust gas thermal power versus engine load

Figure 7: Engine efficiency map. X marks show the points where the engine efficiency has been calculated using the proposed model. Iso-efficiency lines have been produced through triangulation.

Figure 8: Combined MV-0D model results for studying the influence of variable turbine area on the engine performance parameters

Figure 9: Propulsion power demand as a function of ship speed and propeller rotational speed for the case study ship considering operation with $15 \%$ sea margin

Figure 10: Derived parameters for the case study ship versus ship speed for constant and variable engine speed operations

Figure 11: Breakdown of fuel flow demand difference versus ship speed (Positive values refer to higher fuel flow demand in the fixed engine speed case)

\section{List of Table captions}

Table 1: Main parameters for the case study vessel and her propulsion engines

Table 2: Combustion model parameters. Note: * refers to the suggested values for large two-stroke engines; ** refers to the suggested values for heavy duty four-stroke engines; both from [51]

Table 3: Steady state simulation results - comparison between Combined MV-0D model, MVEM and shop trials data 


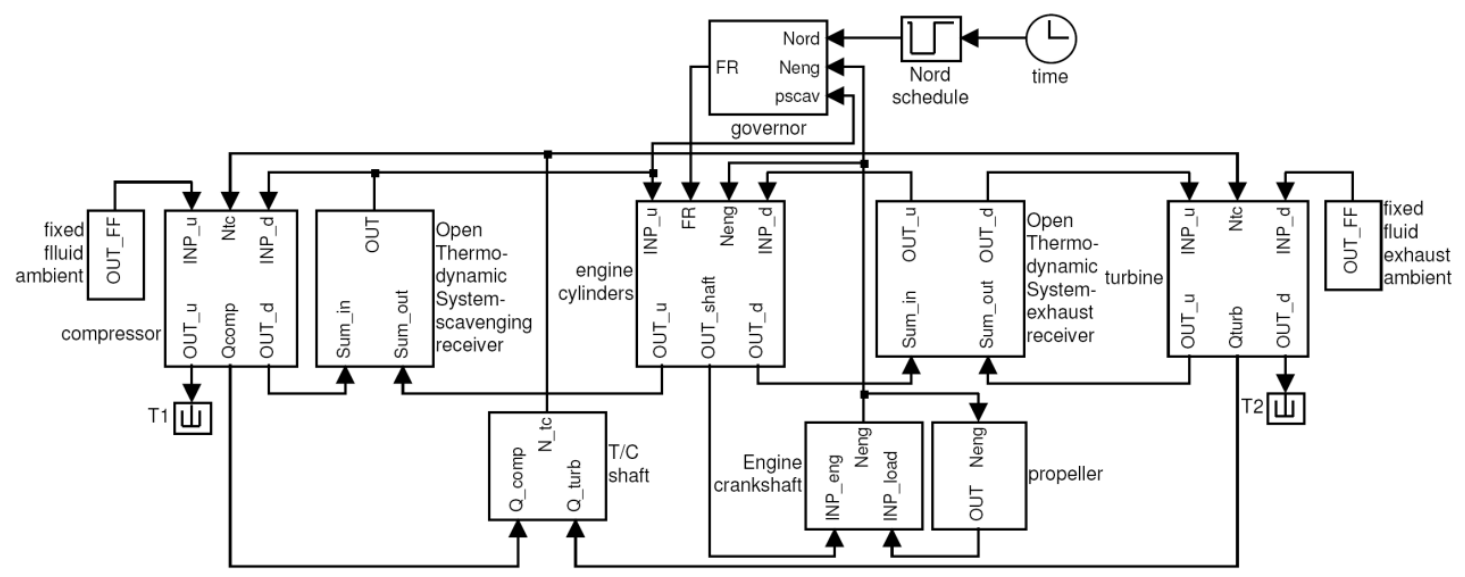

Figure 1: Matlab/Simulink implementation of marine Diesel engine model

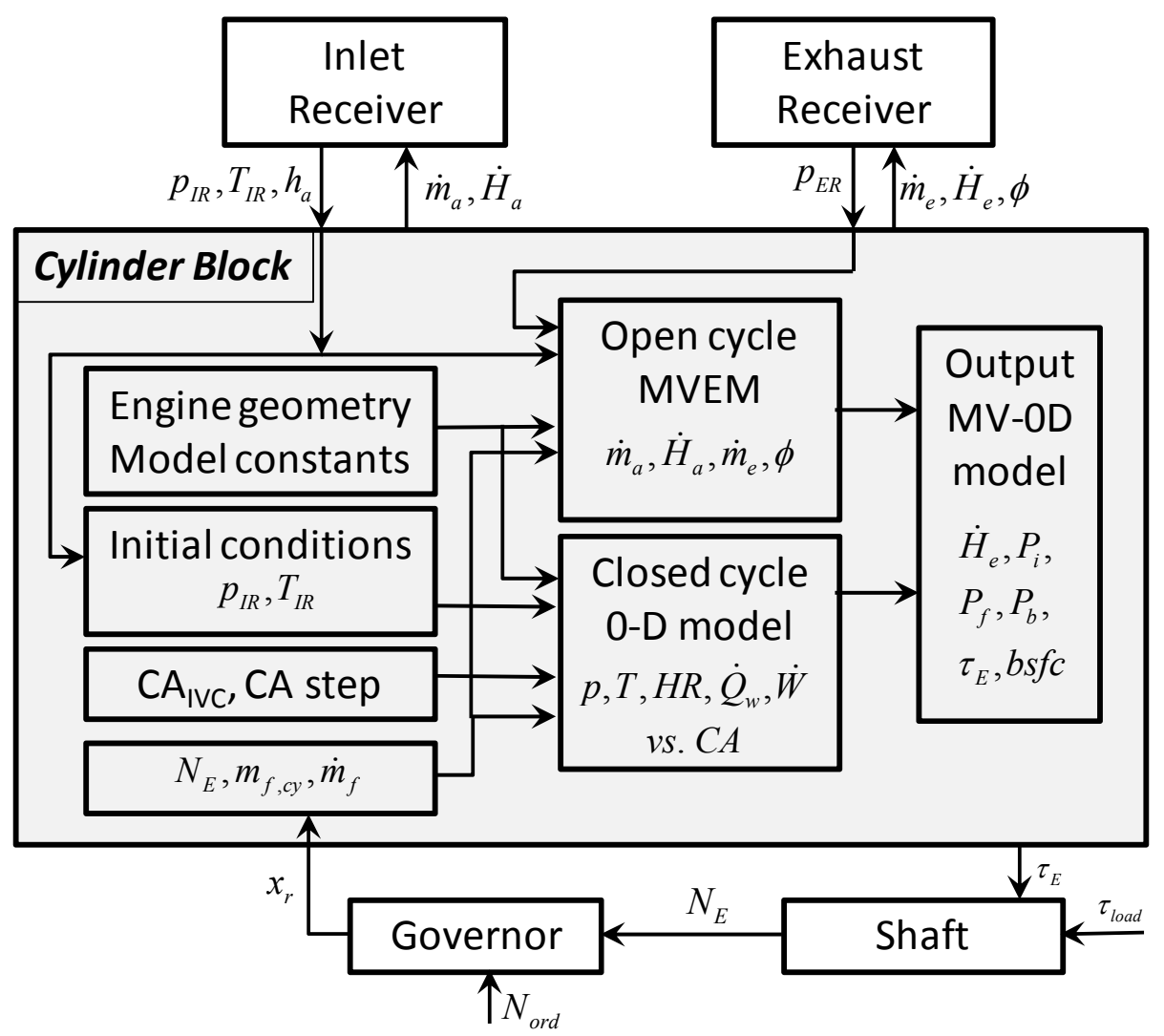

Figure 2: Graphical representation of the interconnections between the combined MV-0D model and the other engine model elements 


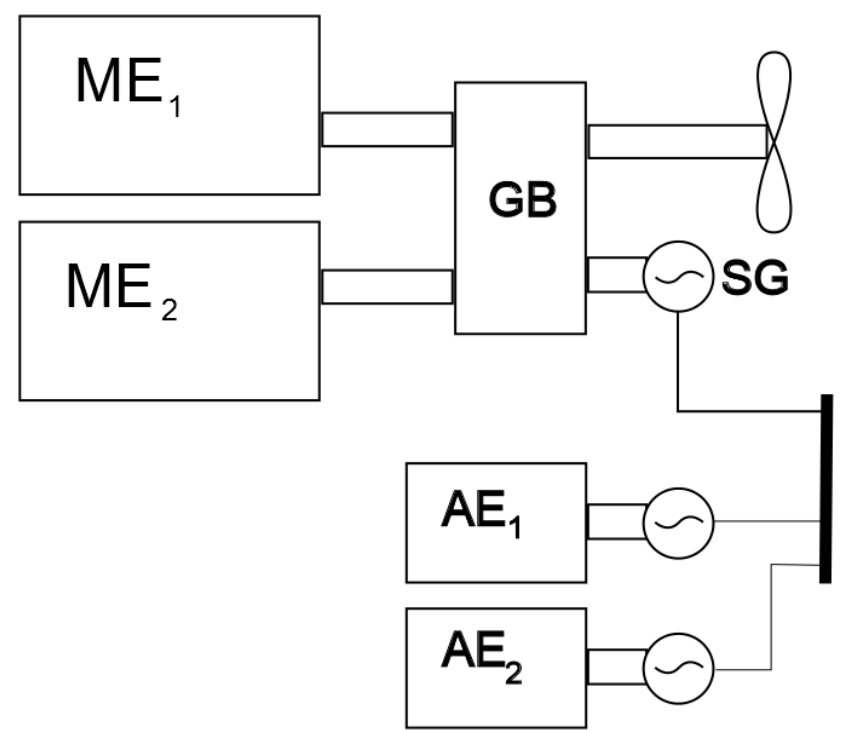

Figure 3: Schematic representation of ship power plant
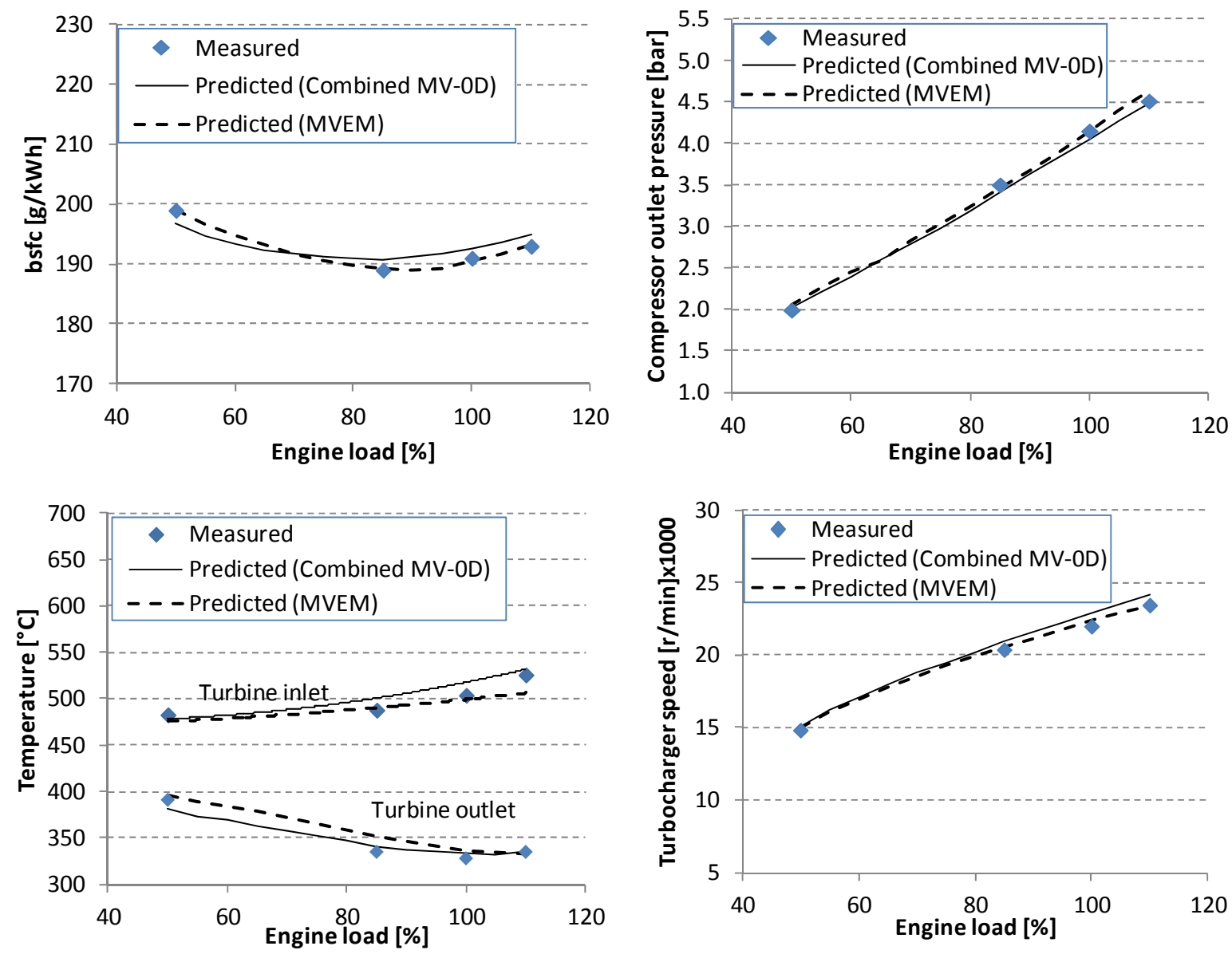

Figure 4: Steady-state simulation results and comparison with shop trials data 


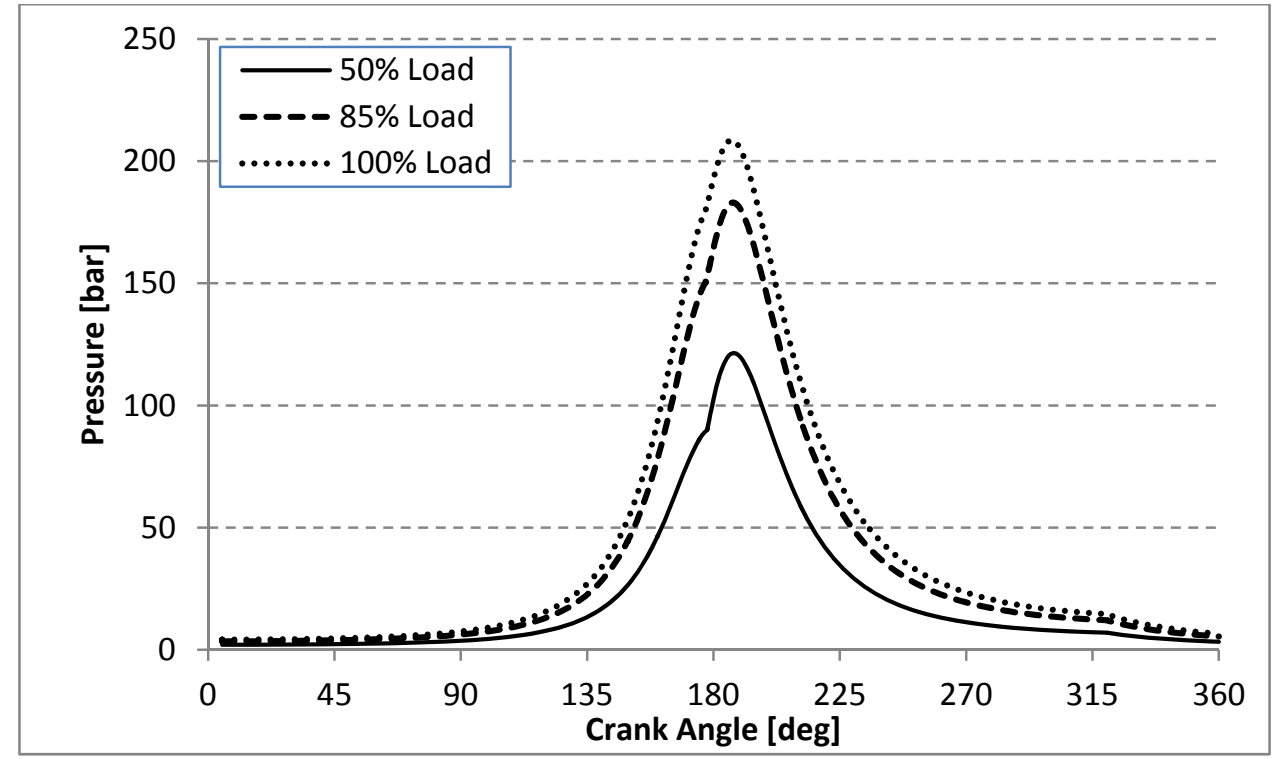

Figure 5: Combined MV-0D model calculated cylinder pressure diagrams for various engine loads

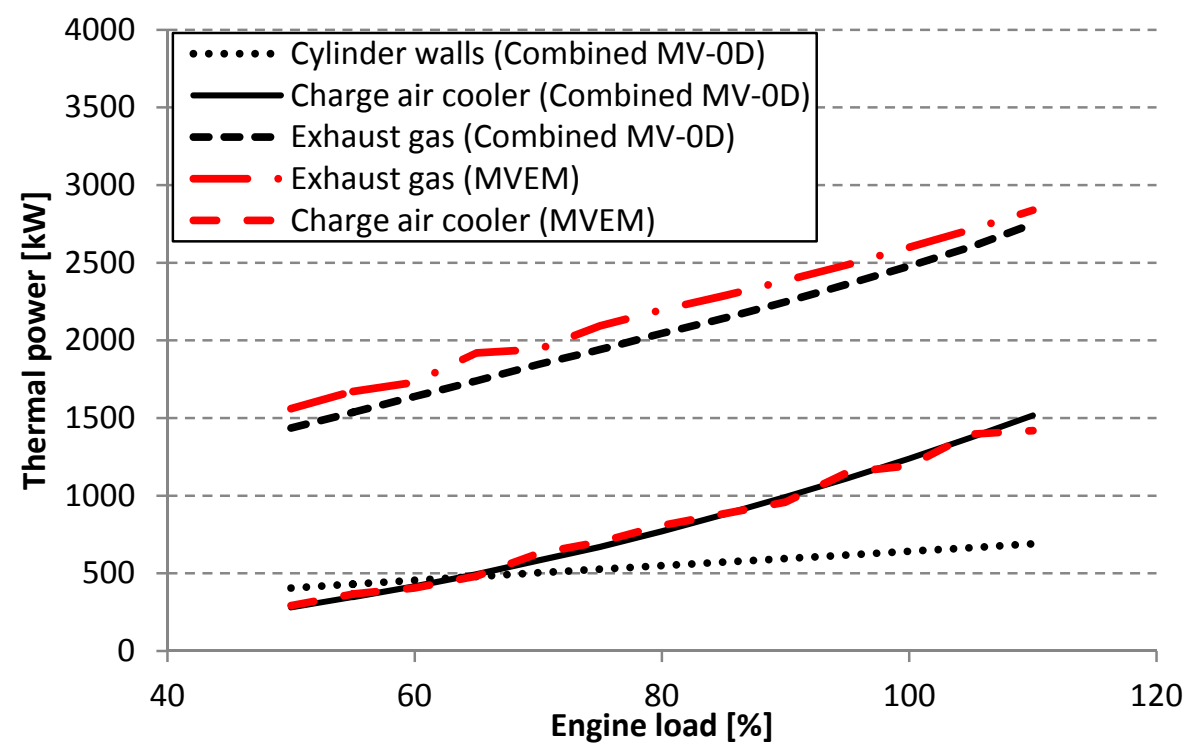

Figure 6: Calculated cooling power and exhaust gas thermal power versus engine load 


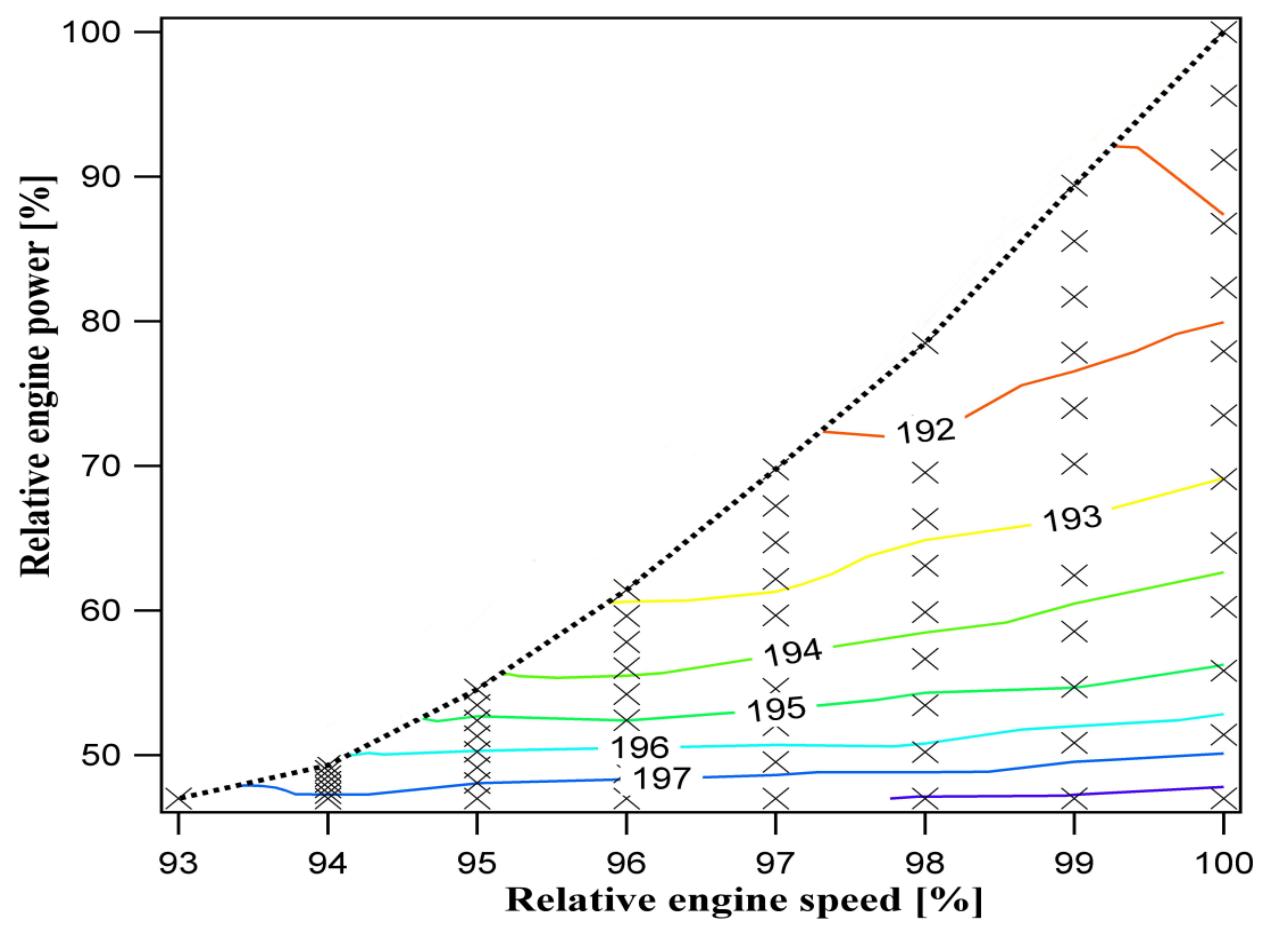

Figure 7: Engine efficiency map. $X$ marks show the points where the engine efficiency has been calculated using the proposed model. Iso-efficiency lines have been produced through triangulation. 

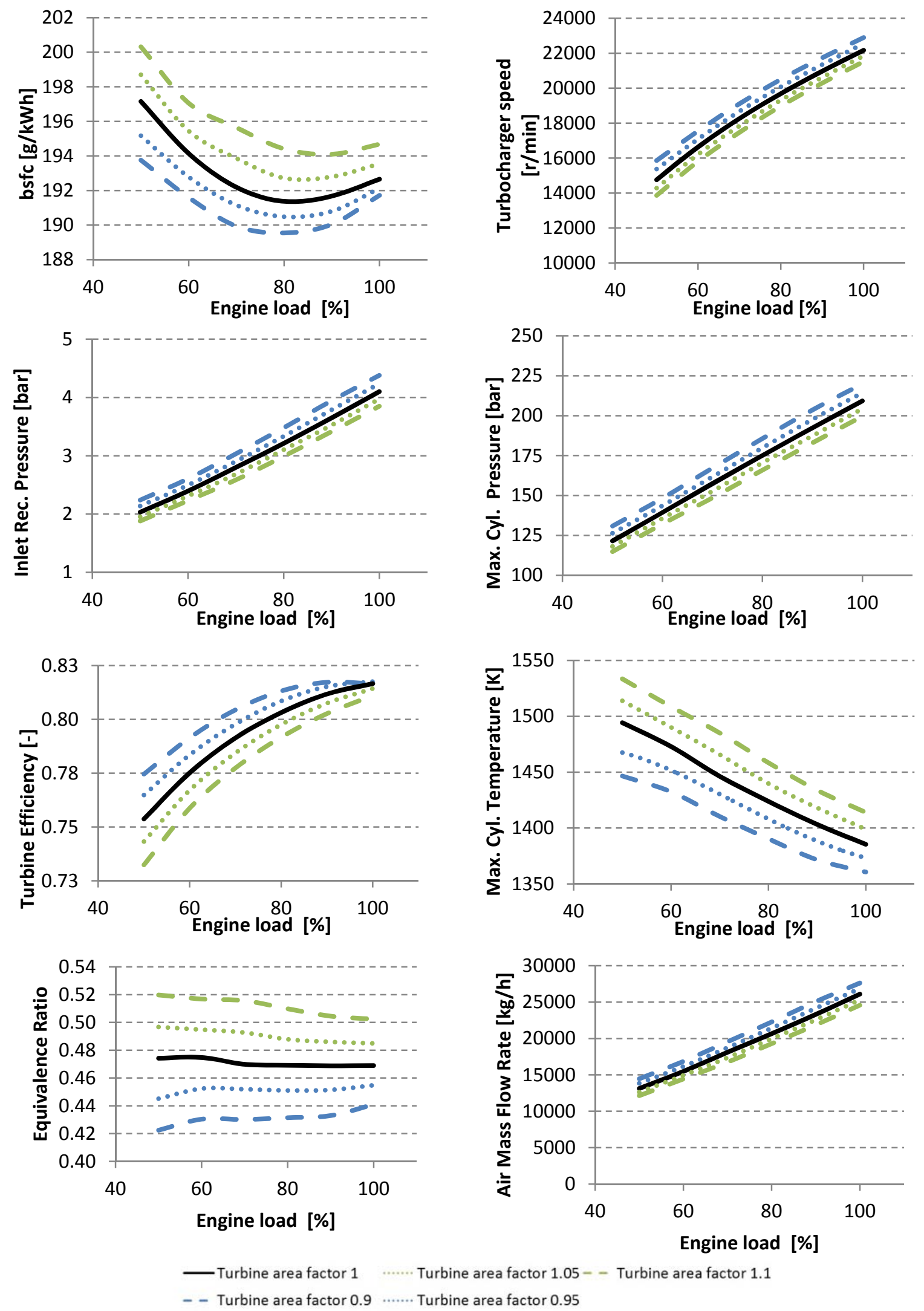

Figure 8: Combined MV-0D model results for studying the influence of variable turbine area on the engine performance parameters 


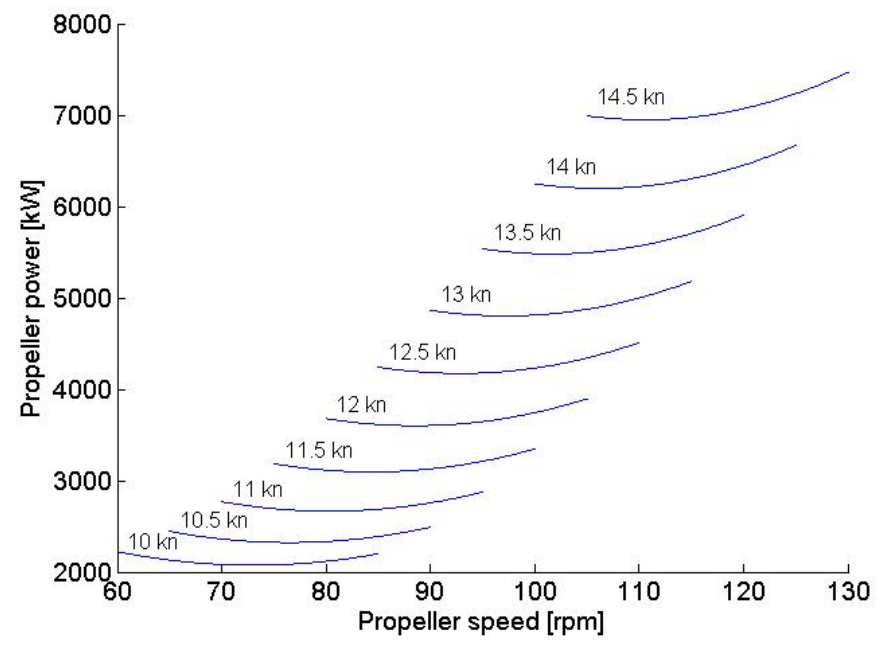

Figure 9: Propulsion power demand as a function of ship speed and propeller rotational speed for the case study ship considering operation with $15 \%$ sea margin 

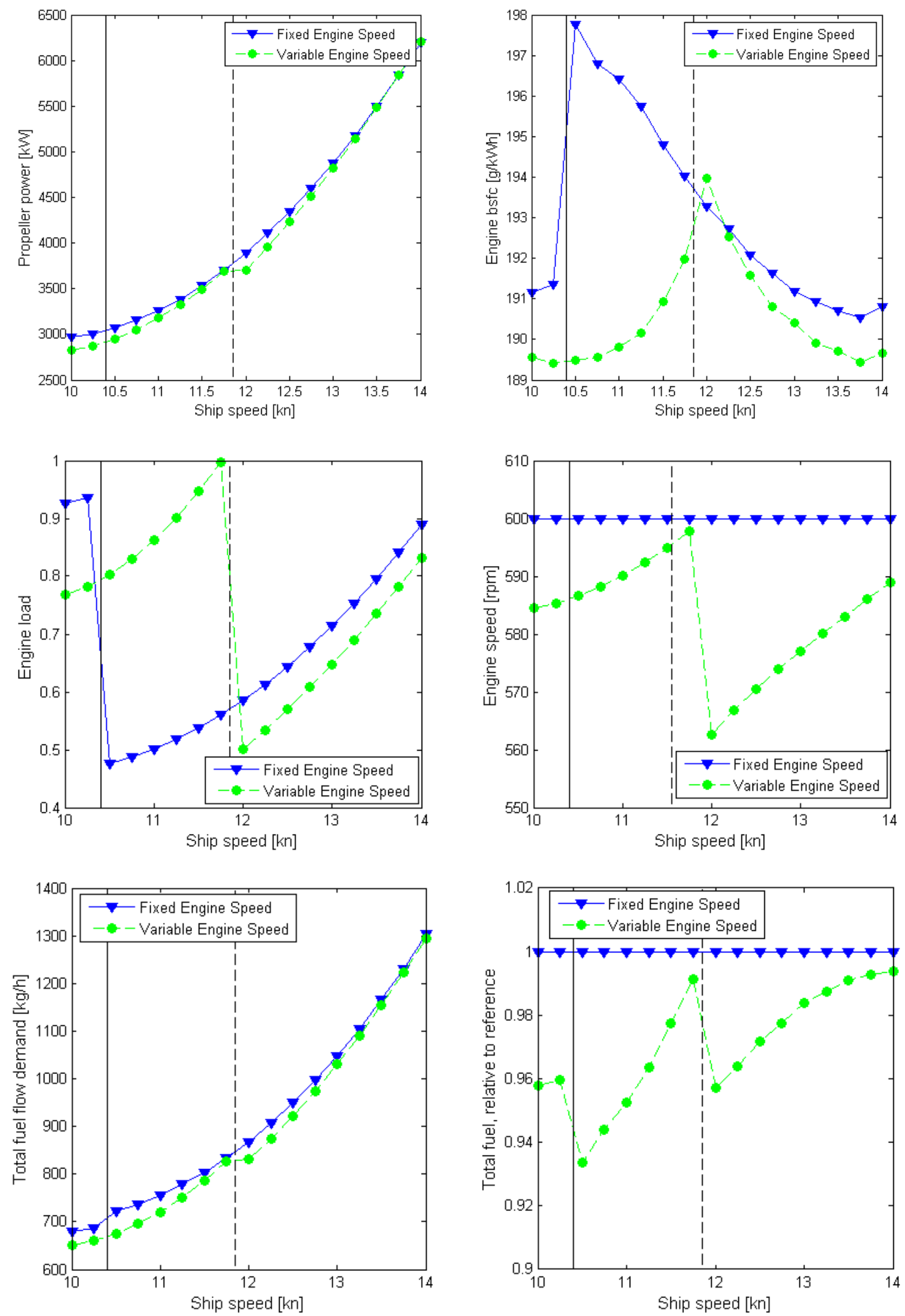

Figure 10: Derived parameters for the case study ship versus ship speed for constant and variable engine speed operations 


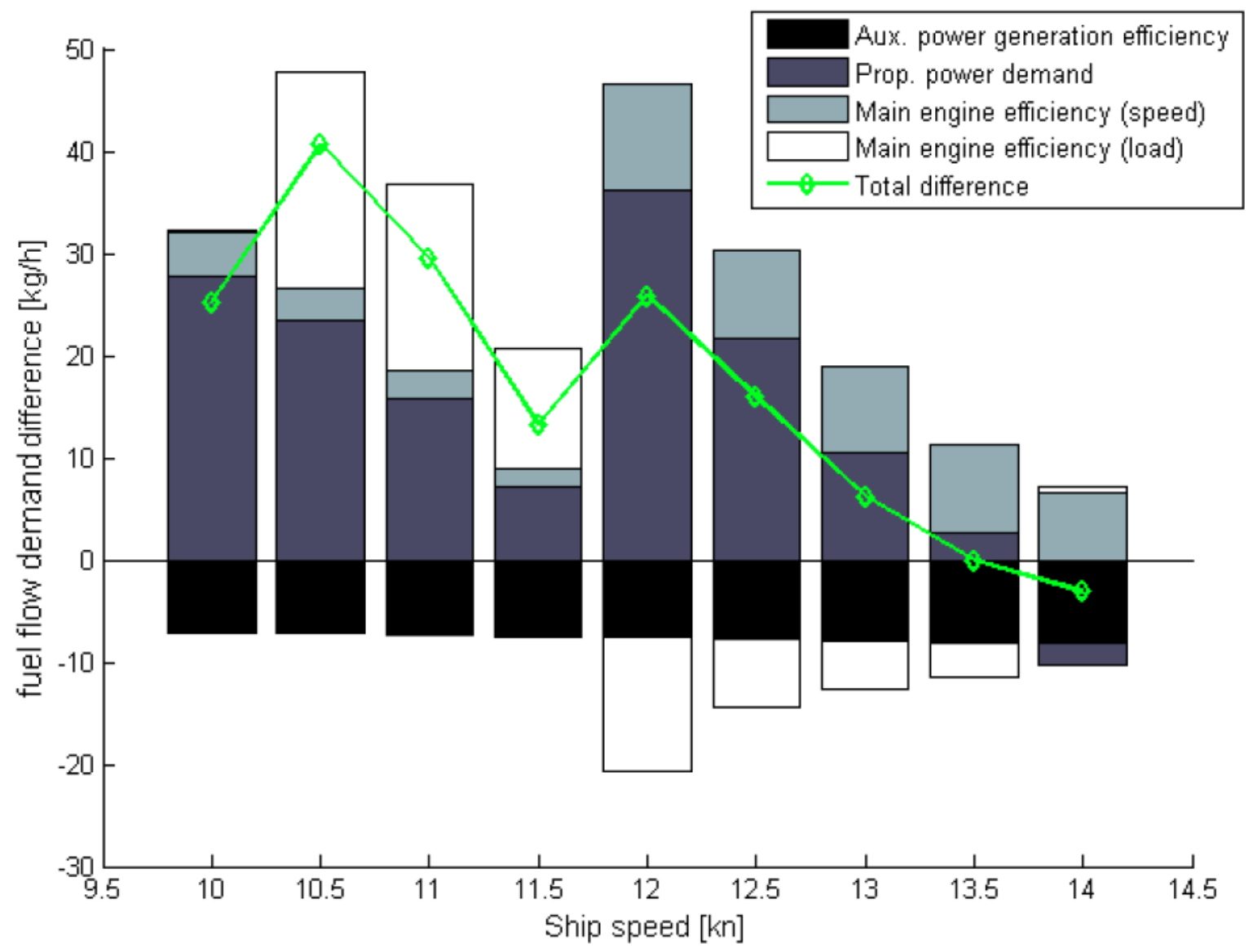

Figure 11: Breakdown of fuel flow demand difference versus ship speed (Positive values refer to higher fuel flow demand in the constant engine speed case) 
Table 1: Main parameters for the case study vessel and her propulsion engines

\begin{tabular}{|cc|}
\hline \multicolumn{2}{|c|}{ Vessel characteristics } \\
\hline $\begin{array}{c}\text { Deadweight } \\
\text { Design speed }\end{array}$ & $47,000 \mathrm{t}$ \\
\hline $\begin{array}{c}\text { Propeller diameter } \\
\text { Number of propeller blades } \\
\text { Type/Size }\end{array}$ & $15 \mathrm{kn}$ \\
Propulsion engines characteristics & $6.0 \mathrm{~m}$ \\
Type & 4 \\
Bore & MaK $8 \mathrm{M} 32 \mathrm{C}$ \\
\hline Stroke & $320 \mathrm{~mm}$ \\
\hline Number of cylinders & $480 \mathrm{~mm}$ \\
\hline Brake power at MCR & 8 \\
\hline Engine speed at MCR & $3840 \mathrm{~kW}$ \\
BMEP at MCR & $600 \mathrm{r} / \mathrm{min}$ \\
\hline Turbocharger units & $24.9 \mathrm{bar}$ \\
\hline
\end{tabular}

Table 2: Calibrated combustion model parameters. Note: * refers to the suggested values for large two-stroke engines; ** refers to the suggested values for heavy duty four-stroke engines; both from [51]

\begin{tabular}{lccrr}
\hline Parameter name & Unit & Lower boundary & Higher boundary & \multicolumn{2}{c}{ Calibrated value } \\
\hline Heat release, $\boldsymbol{\Delta}_{\text {comb,des }}$ & CA degrees & 90 & 110 & 100.3 \\
Heat release, $\mathbf{m}_{\text {comb,des }}$ & {$[-]$} & 0.2 & 1 & 0.2915 \\
Heat release, $\mathbf{a}_{\mathrm{CD}}$ & {$[-]$} & $-0.30^{* *}$ & $0.60^{*}$ & 0.9488 \\
Heat release, $\boldsymbol{\Delta} \mathbf{m}$ & {$[-]$} & $0.00^{*}$ & $0.40^{* *}$ & 0.1919 \\
\hline
\end{tabular}

Table 3: Steady state simulation results, comparison between combined MV-0D model, MVEM and shop trials data

\begin{tabular}{|c|c|c|c|c|c|c|c|c|}
\hline & \multicolumn{2}{|c|}{$50 \%$} & \multicolumn{2}{|c|}{$85 \%$} & \multicolumn{2}{|c|}{$100 \%$} & \multicolumn{2}{|c|}{$110 \%$} \\
\hline & Combined & MVEM & Combined & MVEM & Combined & MVEM & Combined & MVEM \\
\hline SFOC & $1.16 \%$ & $0.5 \%$ & $-0.94 \%$ & $-0.11 \%$ & $-0.80 \%$ & $0.26 \%$ & $-1.04 \%$ & $-0.10 \%$ \\
\hline Inlet pressure & $-1.01 \%$ & $-3.00 \%$ & $2.82 \%$ & $1.42 \%$ & $2.51 \%$ & $0.00 \%$ & $-2.31 \%$ & $-2.43 \%$ \\
\hline $\begin{array}{l}\text { Temperature } \\
\text { at compressor } \\
\text { outlet }\end{array}$ & $5.66 \%$ & $5.63 \%$ & $4.13 \%$ & $5.13 \%$ & $0.47 \%$ & $2.52 \%$ & $-0.38 \%$ & $2.77 \%$ \\
\hline $\begin{array}{l}\text { Temperature } \\
\text { at turbine } \\
\text { inlet }\end{array}$ & $1.26 \%$ & $1.78 \%$ & $-2.17 \%$ & $-0.16 \%$ & $-2.53 \%$ & $1.25 \%$ & $-1.57 \%$ & $3.27 \%$ \\
\hline $\begin{array}{l}\text { Temperature } \\
\text { at turbine } \\
\text { outlet }\end{array}$ & $2.48 \%$ & $-1.36 \%$ & $-1.79 \%$ & $-4.78 \%$ & $-1.79 \%$ & $-2.65 \%$ & $0.09 \%$ & $0.42 \%$ \\
\hline $\begin{array}{l}\text { Turbocharger } \\
\text { speed }\end{array}$ & $-1.41 \%$ & $-1.03 \%$ & $-2.40 \%$ & $-0.74 \%$ & $-3.61 \%$ & $-1.35 \%$ & $-2.67 \%$ & $0.45 \%$ \\
\hline
\end{tabular}


